\title{
The association between strategic group membership and hospital financial performance
}

\author{
Akbar Ghiasi $^{1}$, Robert Weech-Maldonado ${ }^{2}$, Ferhat Zengul $^{2}$, Neeraj Puro ${ }^{3}$ \\ ${ }^{1}$ HEB School of Business \& Administration, University of the Incarnate Word, Broadway, TX, USA; ${ }^{2}$ Department of Health Services Administration, \\ School of Health Professions, The University of Alabama at Birmingham, Birmingham, AL, USA; ${ }^{3}$ Department of Health Administration, College \\ of Business, Florida Atlantic University, Boca Raton, FL, USA \\ Contributions: (I) Conception and design: A Ghiasi, R Weech-Maldonado; (II) Administrative support: R Weech-Maldonado, F Zengul; (III) Provision \\ of study materials or patients: None; (IV) Collection and assembly of data: A Ghiasi, N Puro; (V) Data analysis and interpretation: A Ghiasi, N Puro; \\ (VI) Manuscript writing: All authors; (VII) Final approval of manuscript: All authors. \\ Correspondence to: Akbar Ghiasi, PhD, MHA. Assistant Professor of Health Administration, HEB School of Business \& Administration, University of \\ the Incarnate Word, 4301 Broadway, CPO \#421, San Antonio, TX 78209, USA. Email: ghiasi@uiwtx.edu.
}

Background: The health care industry is facing constant changes from health care reform; demanding consumers; and new expensive forms of treatment. These changes put more pressures on hospitals and their ability to remain profitable. Understanding how to improve hospital financial performance by applying an appropriate strategy increasingly turbulent environment remains a key concern to managers and researchers. The overall purpose of this study was to identify the strategic group structure of the hospital industry and to examine the effect of strategic group membership on hospital financial performance.

Methods: We examined longitudinal data (2006 to 2016) for United States (US) urban general acute care hospitals from three secondary datasets: the American Hospital Association (AHA) Annual Survey, Medicare Cost Reports (CMS), and Area Health Resource File (AHRF). Multiple regression analysis with control for time and state fixed effects was used for data analysis.

Results: Our results suggest that on average about 37 percent of hospitals pursue cost-leadership strategy, and about 5 percent of hospitals pursue the differentiation strategy. Hospitals with hybrid strategy outperform hospitals with cost-leadership strategy and stuck-in-the-middle.

Conclusions: The absence of a coherent strategy (i.e., stuck-in-the-middle) is likely to lead to poor performance. The results demonstrate the usefulness of strategic group studies like this study as a method for managers to assess their current strategic positioning.

Keywords: Strategic group membership; hospital financial performance; competitive advantage; strategic group typology

Received: 17 September 2021; Accepted: 21 January 2022; Published: 25 September 2022.

doi: 10.21037/jhmhp-21-71

View this article at: https://dx.doi.org/10.21037/jhmhp-21-71

\section{Introduction}

Strategy reflects major administrative decisions about the nature of how a hospital competes. Decisions with respect to which services to offer and markets to serve, growth, and pricing are all considered strategic choices (1). Understanding hospital strategy is critical given that these organizations operate in an increasingly dynamic and turbulent environment. In the last decade, the United States (US) healthcare environment has seen a shift in the way healthcare is covered and paid for as a result of the passage of the Patient Protection and Affordable Care Act (PPACA) (2,3). In addition, hospitals are facing financial pressures due to lower reimbursement rates from Medicaid and Medicare, excessive administrative costs, reduced demand for hospital care, increased market competition, 
and staff shortages $(4,5)$. In 2014 , about $15-30 \%$ of hospitals were categorized as financially distressed (6). In an attempt to compete and remain viable in an ever increasingly turbulent and competitive environment (5), hospitals are adopting strategies that improve their financial performance. As such, managers need to understand how hospital strategy may impact its financial performance.

In this study, we used the strategic group membership model (7) to identify hospitals' strategies. The strategic group is a concept used in the strategic management literature that groups firms within an industry that have similar business models or similar combinations of strategies $(7,8)$. The strategic group model offers a specific typology for decision-makers to conceptualize strategic positioning and a unique basis to compare the resources required to implement alternative strategies.

Prior research has found differential financial performance based on hospital strategic group membership (9-11). For example, Marlin et al. found that hat low-cost and best-cost (hybrid) firms outperformed differentiators, which outperformed muddlers (stuck-in-the middle) (10). However, these studies were conducted using data prior to 2000; significant health care environmental changes since 2000 may have influenced hospitals' strategic group membership and its relationship with financial performance. Furthermore, these studies were limited to a single state or region, which limits the generalizability of study findings. This study contributes to the extant literature by examining a US national sample of hospitals, using longitudinal data from 2006 to 2016, and reexamining hospitals' strategic group membership and its relationship with financial performance.

The development of effective strategic responses to environmental change is critical to the long-term survival and performance of hospitals. The strategic group model offers a specific typology for managers to conceptualize their competitive strategies and a unique method to compare the resources required to implement each competitive strategy. The identification of a competitive strategy could be challenging for managers, given time constraints and limitations in information processing.

Strategic groups are groups of organizations within a specific industry $(7,12)$ with similar competitive strategies (e.g., technological leadership, innovation, customer service, efficiency, pricing) (13) and similar organizational characteristics (e.g., skills, products or services, size, and organizational structure); but with different strategies and organizational characteristics from other strategic groups
$(14,15)$. Strategic groups are assumed to be highly stable due to mobility barriers. McGee \& Thomas (16) define mobility barriers as either the absolute cost of moving from one strategic group to another, as an operating cost, relative to the strategic group incumbents, that the new entrant must (16). Mobility barriers can include tangible and intangible resources such as assets, technology, skills, reputation, brand loyalty, and so on (16-18). These barriers protect each strategic group from outside competition and may lead to performance differences (19).

The evolution of strategic group research has produced two distinct grouping approaches: inductive and deductive approaches. The inductive approach focuses on empirically derived configurations (20). For instance, many strategic group studies have clustered organizations on a variety of industry-specific measures consisting of manufacturing, marketing, and financial characteristics. The inductive approach provides no theoretical reasoning to expect a specific number of strategic groups in any given industry. In contrast, a deductive approach is a theory-driven approach that specifies generic strategies that can be applied to a wide variety of industry contexts. Given our overarching interest in comparing our findings with other studies, we relied on a deductive approach that offers superior generalizability relative to inductive approaches $(11,20)$.

In the present study, we relied on Porter's (8) Generic Strategy typology to define hospital strategic groups for several reasons. First, researchers have confirmed the reliability of this typology for grouping firms in strategic groups $(21,22)$. Second, this typology has received empirical support from previous research regarding the association between strategic grouping and financial performance (18,23-25). Third, prior research has supported the applicability of Porter's typology to the hospital industry $(10,26,27)$. Although healthcare is different from other industries in many aspects such as the nature of services (e.g., outcomes are not certain), pricing and payments by third party, and large presence of non-for-profit organizations (28), the studies have shown some similarity between healthcare industry and other industries (29) and also several studies have shown the application of Porter's strategic grouping typology in healthcare, especially hospitals $(21,22)$. Finally, Porter's typology allows us to compare the results of this study with the findings of other studies (20).

Porter's Generic Strategy typology defines how a firm gains a competitive advantage in its chosen market. Cost leadership and differentiation are two generic strategies 
that a firm may use (Porter's original typology includes focus strategy, however because we only focused on general acute care hospitals, we did not discussed it in this paper) to gain a competitive advantage in a market, which may result in firm performance differences (13). Firms that pursue a cost leadership strategy achieve competitive advantage by becoming the low-cost producers in each industry (8). Cost leaders emphasize cost reduction mechanisms such as those achieved from production experience, by building efficient-scale facilities, and by minimizing costs in areas such as marketing, R\&D, staffing, and overhead $(13,14)$. The adaptation of a low-cost or cost leadership strategy would primarily consist of achieving a lower per-unit cost of products or services and increasing marginal profit per unit product or services (30). Examples of cost control strategies used by hospitals include eliminating marginally profitable and unprofitable services, reducing waste by eliminating repetitive procedures, reducing staff, improving efficiency, using technology, innovating, and improving interfunctional coordination (31). In the hospital industry, payers like Medicare, Medicaid and private payers determine the price of services (32). Also, different payment systems from third-party payers such as prospective payment systems, per diem payment, or bundled (global) payment emphasize efficiency and encourage cost-containment strategies $(33,34)$. Although in healthcare industry providers like hospitals do not determine the price of services (32) but they enjoy higher profit margin per services by focusing on lowering their cost and eventually attain better financial performance.

Differentiators, on the other hand, attempt to develop unique products or services. These firms may command higher revenues than competitors to justify the higher costs of producing unique products or services (8). Differentiators focus on the breadth of product or service offerings, high technology, or customer service. Approaches to differentiating hospital services have been varied. Studies have shown that hospitals may implement a differentiation strategy by developing a "high tech" image using the latest (and most expensive) technologies (e.g., such as organ transplant, magnetic resonance imaging, cardiac surgery, robotic surgery); depicting a high-quality image; offering services not commonly offered (e.g., transplant services, open heart surgery); and providing centers of excellence around particular disease categories, such as women's health or cardiac care $(31,35,36)$. In general, hospitals pursuing a differentiation strategy offer patients unique services that provide value to patients by satisfying their needs.
By meeting market needs for these unique services with higher technology, hospitals attempt to create a competitive advantage over their rivals $(31,37)$. The higher technology services imply uniqueness of services, and it shows hospitals investing in such services to create different image in their market. Studies have shown that patients are more likely to choose large (in terms of hospital capacity) and high-volume (the number of previous admissions) hospitals that offer a more sophisticated range of services $(38,39)$. Hospitals' provision of unique or high-tech services may result in better reimbursement (40). In addition, by providing the latest technology, hospitals may portray an image of higher quality and may be better able to attract medical staff (41-43).

According to Porter (8), either cost leadership or differentiation can result in a competitive advantage. Therefore, pursuing either strategy should result in similar financial performance.

(I) H1: Hospitals with a cost leadership strategy and those with a differentiation strategy have similar financial performance.

Porter (8) described the cost leadership and differentiation strategies as being mutually exclusive because each represents fundamentally different approaches to building and sustaining a competitive advantage. The benefits of optimizing a strategy cannot be gained if the firm is simultaneously pursuing more than one generic strategy at time. Thus, successful organizations would exclusively compete on one of the two generic strategies. However, some researchers have argued that differentiation and cost leadership can be viewed as separate dimensions along which firms can score low and high. Through a hybrid strategy or best-cost strategy $(30,31,44,45)$, a firm may simultaneously and successfully pursue both the cost leadership and differentiation strategies $(27,46)$.

A hybrid strategy may be achieved in two main ways. First, the implementation of a differentiation strategy promotes uniqueness, mainly through higher perceived quality and unique products or services. Higher perceived quality and uniqueness would presumably lead to greater market demand and ultimately higher market share, allowing the firm to reduce costs through increased economies of scale $(13,47)$. Second, an organization may pursue a differentiation strategy with some highercost services but undertake a cost-leadership with some services that may be more conducive to efficiency gains. For example, hospitals may offer some high-tech services such as organ transplant, magnetic resonance imaging, 
cardiac surgery, or robotic surgery, to capture a wide range of services to differentiate themselves from rivals, but at the same time may apply some cost containment strategies, such as eliminating unprofitable services, reducing waste by eliminating repetitive procedures, reducing staff, improving efficiency, innovating, etc. $(36,48)$.

Firms that compete with a hybrid strategy may surpass those that pursue either cost leadership or differentiation strategy (30). One reason could be the mutually reinforcing benefits of a hospital's emphasis on product, services, quality, process innovation, and cost control. Prior research has shown that hospitals can pursue a hybrid strategy successfully with potentially better financial outcomes than those pursuing a pure generic strategy $(31,44,49)$. Thus, we propose that:

(II) H2: Hospitals with a hybrid strategy financially outperform hospitals with a cost leadership strategy.

(III) H3: Hospitals with a hybrid strategy financially outperform hospitals with a differentiation strategy.

Firms that are not completely committed to the cost leadership, differentiation, or hybrid strategy, utilize no strategy and are referred to as "stuck-in-the-middle" or "muddlers (8). Firms that pursue a cost-leadership, differentiation, or hybrid strategy are expected to have better financial performance compared to firms that are stuck-in-the-middle (hospitals with high cost and low differentiation characteristics). Thus, we hypothesize that:

(IV) H4: Hospitals with a cost leadership, differentiation, and hybrid strategies financially outperform hospitals with a stuck-in-the-middle strategy.

\section{Methods}

We used three secondary datasets from 2006 through 2016. The dramatic changes that swept through the hospital industry during the last decade have placed hospitals in choice situations very different from what they were experiencing before. Using longitudinal data is helpful to capture the strategic choice of hospitals effectively and comprehensively. the American Hospital Association (AHA) Annual Survey provided general organizational information about hospitals. Second, Medicare Cost Reports provided financial performance data. Third, the Area Health Resource File (AHRF) included county-level characteristics of the hospital markets. Observations across these three datasets were merged using Medicare Provider Numbers and FIPS county and state codes.

The sample consisted of all private, urban (an acute care hospital that is located within a metropolitan statistical area (50), general acute care hospitals in the United States. Our goal was to have a hospital sample with similar environmental and competitive pressures in examining strategy. Public, rural, and specialty hospitals face a different operating and competitive environment compared to private, urban, and general acute hospitals (51). After excluding public, rural and specialty hospitals, we had 29,518. After cleaning up our data and dropping some hospitals due to missing values the final sample size consisted of 23,570 hospital-year observations (or an average of 2,700 hospitals per year).

The dependent variable was operating margin (Net Patient Revenue - Operating Costs/Net Patient Revenue), a commonly used financial performance measure in the health care literature (20,48,52-54). This variable measures the profitability and efficiency of the hospital operations (55). We used operating margin which focuses on core business functions of hospitals (profit from patient care) and excludes the influence of non-operating income like endowments and non-operating expenses such as interest income (56).

The main independent variable was a categorical variable identifying hospital membership in one of four strategic groups: cost-leadership, differentiation, hybrid, and stuckin-the-middle. We used Porter's strategic group framework to determine the strategic group membership of each hospital. According to this typology, each strategy can be operationalized using two dimensions: cost-leadership and differentiation (13). Three main measures have been used to operationalize cost leadership in the strategic group literature in the hospital context: total expenses to the number of occupied beds, the total cost per patient day, and total salaries per patient day $(9,49,53)$. By dividing total expenses by the number of beds occupied, we can ascertain the hospital's expense rate based on its current level of business. Total cost and salary per patient day also express how efficiently internal finances are managed based on current business (49). As expected, we found strong positive correlations among the three cost leadership variables in each year.

Three main measures have been employed in the literature to operationalize the differentiation dimension: the total number of provided services, the number of hightech services, and the number of rare services $(9,49,53)$. The total number of services represents the sum of all services provided by each hospital, of a possible 135 services identified in the American Hospital Association's Guide to the Health Care Field. The second measure is 
Table 1 Identified strategic groups based on cluster analysis results in $2016^{*}(\mathrm{~N}=2,524)$

\begin{tabular}{|c|c|c|c|c|c|}
\hline $\begin{array}{l}\text { Cluster } \\
\text { groups }\end{array}$ & $\begin{array}{l}\text { Cost-leadership composite } \\
\text { score (mean) }\end{array}$ & Cost leadership rank & $\begin{array}{l}\text { Differentiation composite } \\
\text { score (mean) }\end{array}$ & Differentiation rank & $\begin{array}{l}\text { Identified strategic } \\
\text { group }\end{array}$ \\
\hline 1 & 0.7856686 & 4 & 2.412101 & 1 & Differentiation \\
\hline 3 & 0.0306939 & 2 & 0.7303677 & 2 & Hybrid \\
\hline
\end{tabular}

${ }^{*}$, the lowest score on cost leadership composite is ranked 1 , while the highest score differentiation composite is ranked 1.

the total number of high-tech services, which represents the sum of hospital services requiring the most updated technology (i.e., a cardiac catheterization laboratory, an extracorporeal lithotripter, magnetic resonance imaging, open-heart surgery, and organ transplantation capability) $(9,49)$. Hospitals may invest in such services to differentiate themselves from rivals. The number of rare services represents the sum of hospital services that are offered by less than 10 percent of all the hospitals (49). The American Hospital Association's Guide to the Health Care Field was used to identify the rare services (services may have been offered for patients with complex conditions (57). A higher number of rare services may indicate investing in services for patients with complicated cases that are not offered by many competitors. Also, hospitals may use rare services to create an image of uniqueness or high quality. Similar to the low-cost leadership measures, we found strong positive correlations among the three differentiation variables in each year. Due to these positive correlations, we decided to create composite scores for both the cost-leadership and differentiation indicators.

To create composite scores of the cost-leadership and differentiation measures, we first confirmed the unidimensionality of each construct through factor analysis. The analysis yielded two factors with eigenvalues greater than 1. One factor included the three differentiation measures. The second factor included the three cost leadership measures. Finally, composite scores of cost leadership and differentiation dimensions were calculated by, first, standardizing the three measures for each composite as $Z$-scores [ $(x-$ mean of $x) /$ standard deviation] (58), and then summing the three $Z$-scores for each dimension.

We used the composite scores for cost-leadership and differentiation to determine the hospital's strategic groups. A two-stage clustering procedure (hierarchical and nonhierarchical clustering) (58) was used to increase the validity of the cluster solution $(31,51)$. In the hierarchical procedure (agglomerative method), each object or observation begins as a separate cluster. In each subsequent step, the two most similar clusters are combined to build a new aggregate cluster. Ward's hierarchical method was used to determine the number of clusters/groups (58). In the Ward's method, the similarity is determined by the sum of squares within the clusters summed over all variables. Appendix 1 outlines the criteria used to identify the optimal cluster solutions based on the Ward's method.

After identifying the optimal cluster solution based on the Ward's method, we used the K-Means clustering method to group hospitals in strategic groups. The $\mathrm{K}-\mathrm{Means}$ method is a non-hierarchical clustering that groups observations based on a researcher-specified number of clusters (58). Since we obtained a four-group solution hierarchical clustering, we performed K-Means by 4 groups. After performing the K-Means clustering, the four groups were labeled based on their mean composite scores of cost leadership and differentiation dimensions. To accomplish this step, first, we ranked the four groups that resulted from the K-Means cluster analysis based on their mean composite scores for cost-leadership and differentiation. Second, we identified the group with the lowest cost composite score $\left(1^{\text {st }}\right.$ in rank) and low differentiation score (e.g., $3^{\text {rd }}$ in rank) as a "Cost-Leadership" group. We labeled "Differentiation" as the group with the highest differentiation composite score $\left(1^{\text {st }}\right.$ in the rank) and the highest cost score (e.g., $3^{\text {rd }}$ in rank). We identified "Hybrid" as a better-ranked in both costleadership composite score and differentiation compared to stuck-in-the-middle (sum of the two ranks). In addition, the hybrid has better differentiation scores than cost leaders, and lower costs than differentiators. Finally, we identified "Stuck-in-the-middle" as the worst-ranked in both costleadership and differentiation composite score mean (sum of the two ranks; please see Table 1 for more details).

Control Variables. Organizational characteristics might 
Table 2 Proportion of hospitals by strategic group (2006 to 2016)

\begin{tabular}{lcccccccccccc}
\hline Strategy & 2006 & 2007 & 2008 & 2009 & 2010 & 2011 & 2012 & 2013 & 2014 & 2015 & 2016 \\
\hline Cost-leadership & $38.9 \%$ & $42.4 \%$ & $27.8 \%$ & $29.2 \%$ & $40.7 \%$ & $42.5 \%$ & $40.5 \%$ & $39.6 \%$ & $41.6 \%$ & $40.7 \%$ & $40.5 \%$ \\
Differentiation & $5.4 \%$ & $3.8 \%$ & $4.5 \%$ & $4.3 \%$ & $5.1 \%$ & $4.9 \%$ & $4.7 \%$ & $5.1 \%$ & $4.2 \%$ & $5.3 \%$ & $4.3 \%$ & $24 \%$ \\
Hybrid & $27.8 \%$ & $25.5 \%$ & $42.1 \%$ & $24.9 \%$ & $26.5 \%$ & $24.4 \%$ & $24.3 \%$ & $26.2 \%$ & $23.5 \%$ & $26.6 \%$ & $27.1 \%$ \\
Stuck-in-the-middle & $27.9 \%$ & $28.3 \%$ & $25.6 \%$ & $41.6 \%$ & $27.7 \%$ & $28.2 \%$ & $30.5 \%$ & $29.1 \%$ & $30.7 \%$ & $27.4 \%$ & $28.1 \%$ \\
Total & $100.0 \%$ & $100.0 \%$ & $100.0 \%$ & $100.0 \%$ & $100.0 \%$ & $100.0 \%$ & $100.0 \%$ & $100.0 \%$ & $100.0 \%$ & $100.0 \%$ & $100.0 \%$ \\
\hline
\end{tabular}

have a substantial impact on the financial performance of hospitals $(31,51,54,59)$. Following previous studies, we controlled for organizational characteristics including size (number of hospital beds), Medicare payer mix (proportion of Medicare patients), Medicaid payer mix (proportion of Medicaid patients), system affiliation (1 if affiliated to the system, 0 if non-affiliated), ownership type ( 1 if not-forprofit, 0 if for profit), and teaching status ( 1 if teaching, 0 if non-teaching).

Previous studies also have shown that some environmental or market variables might affect the financial performance of hospitals (54). In this study, we controlled for hospital competition, which was measured by the Herfindahl-Hirschman Index (HHI), an indicator of market concentration that is calculated by taking the sum of the squared market shares for hospitals in a Health Service Area (HSA). Market share, which is the proportion of hospitals' average inpatient days in relation to the total inpatient days in a given market, was calculated from the AHA Annual Survey (60). Other environmental variables included per capita income (total household income in the county/total population of the county), unemployment rate (number of unemployed individuals in the current year/total population in the county), and percent population 65 years and older (number of population 65 years and older in the county/ total population in the county).

\section{Statistical analysis}

The unit of analysis was the hospital. For bivariate analysis, we conducted ANOVA to analyze the relationship between the continuous dependent and independent variables and the strategic group membership variable, and chi-square to analyze the relationship between the dichotomous independent variables and the strategic group membership variable. We used generalized estimating equation (GEE) regression for the multivariate analysis. Rather than modeling the within-subject covariance structure, GEE treats it as a nuisance and simply models the mean response (61). We controlled for organizational and environmental factors. To partially address potential issues of endogeneity between strategic group membership and the outcome variable, we used 1-year lagged variables for the strategic group membership variables. Finally, we included state fixed effects to control for interstate differences in the policy environment, and year fixed effects to control for time trend. We reported beta coefficients for significant associations. SAS 9.4 and Stata 15 were used for data management and data analyses. we used $\mathrm{P}$ value $\leq 0.05$ for our significance level.

\section{Results}

The cluster analysis procedure resulted in four clusters in each year using Ward's method and K-Means clustering. Table 2 provides the distribution of each strategic group from 2006 to 2016. The cost-leadership strategy was the most pursued during the 11-year study period. On the other hand, the differentiation strategy was the least pursued strategy during the same period. Moreover, there was a fluctuation of hospital strategic group membership before 2010 and stability after 2010. Analysis of variance and chi-square test results for the relationship between the independent and dependent variables with strategic groups are presented in Table 3. We found significant differences across the four strategic groups in all dependent and independent variables except HHI, suggesting that the cluster analyses produced distinct clusters. Hybrids have the highest (1.29) operating margin, and the stuck-in-themiddle group has the lowest $(-0.46)$ operating margin. While 99 percent of hospitals in the cost-leadership group are non-teaching, $78 \%$ of hospitals in the differentiation group are teaching hospitals. Hospitals in the differentiation group are the largest with an average size of 370 beds. 
Table 3 Descriptive analyses of dependent and independent variables by strategic group (2016)

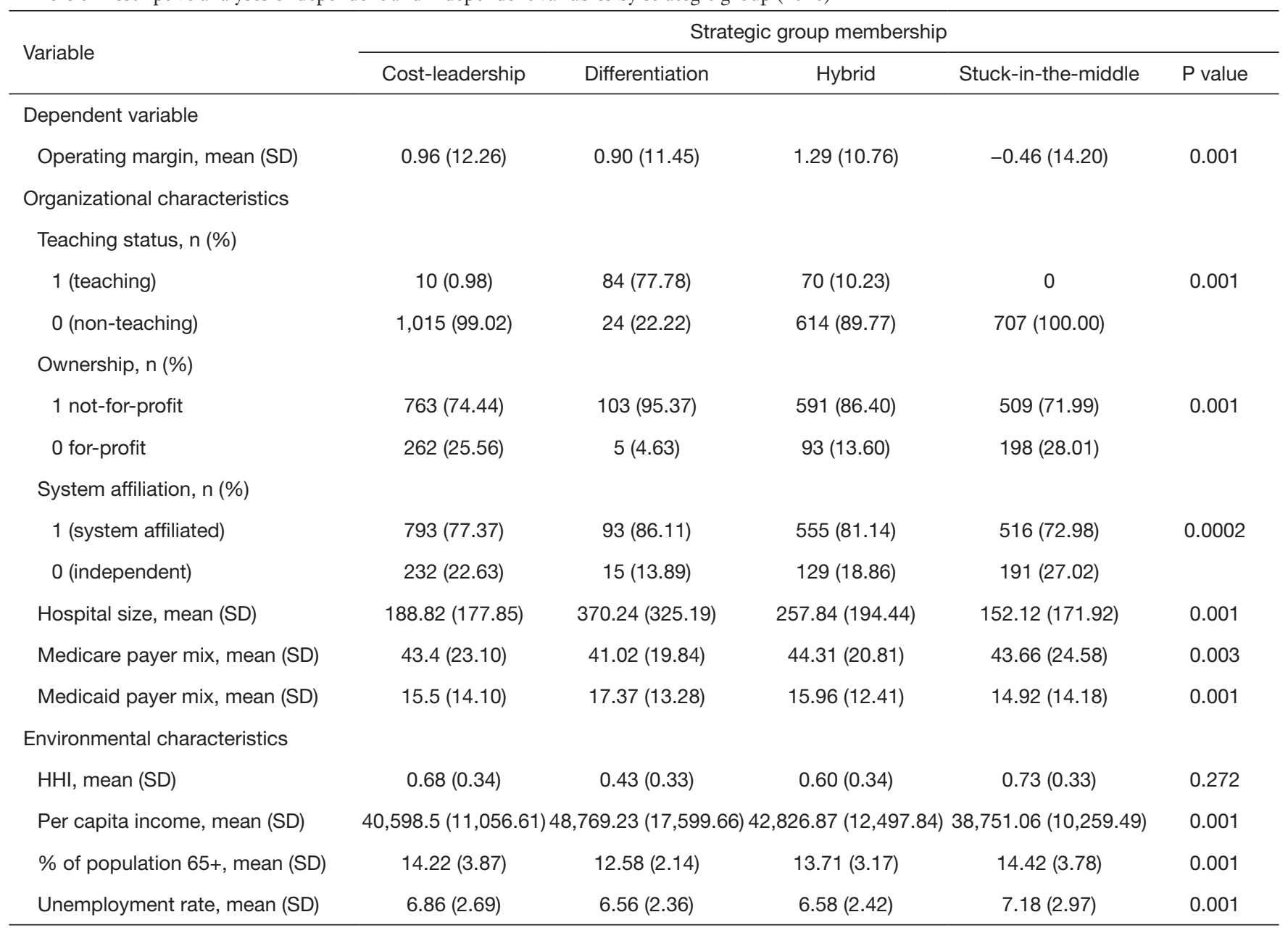

$\mathrm{HHI}$, Herfindahl-Hirschman Index; SD, standard deviation.

On the other hand, hospitals in the stuck-in-the-middle group are the smallest with an average size of 152 beds. In terms of the hospital environment, differentiators are in environments with higher per capita income and lower population $65^{+}$.

The results of the GEE regression and pairwise comparison of the strategic groups' beta coefficients is presented in Tables 4,5, respectively. Hypothesis one posits that hospitals with a cost leadership strategy and those with a differentiation strategy have similar financial performance. Our regression results support this hypothesis, since there was no statistical difference between hospitals in the cost leadership strategic group and those in the differentiation strategic group. Hypothesis 2 indicates that hospitals with a hybrid strategy financially outperform hospitals with a cost leadership strategy. Our findings supported this hypothesis, since it showed that hospitals in the cost leadership strategic group have a 0.41 percent lower operating margin compared to hospitals in the hybrid strategic group. On the other hand, we did not find support for hypothesis 3 that hospitals with a hybrid strategy financially outperform hospitals with a differentiation strategy.

Hypothesis 4 states that hospitals with a cost leadership, differentiation, and hybrid strategies financially outperform hospitals with a stuck-in-the-middle group. The results of the analysis supported our hypothesis. Indeed, hospitals in the stuck-in-the-middle group have 0.38 percent less operating margin compared to hospitals in the costleadership group $(\mathrm{P}<0.05)$. The results supported our hypothesis in terms of differentiators have between financial performance compared to stuck-in-the-middle hospitals, hospitals in the stuck-in-the-middle strategic group have a 
Table 4 Regression of the relationship between strategic group membership and operating margin $(\mathrm{N}=23,387)$

\begin{tabular}{lc}
\hline Variables & $\begin{array}{c}\text { Operating margin, beta } \\
\text { coefficient (SE) }\end{array}$ \\
\hline Strategic group membership (ref: hybrid) & \\
Cost-leadership & $-0.41(0.17)^{\star \star}$ \\
Differentiation & $0.184(0.52)$ \\
Stuck-in-the-middle & $-0.79(0.18)^{\star \star \star}$ \\
Organizational characteristics & \\
Teaching status (1 if teaching) & $-1.47(0.59)^{\star \star}$ \\
Ownership (1 if not-for-profit) & $-4.53(0.33)^{\star \star \star}$ \\
Hospital size & $0.0003(0.001)$ \\
System affiliation (1 if system affiliated) & $0.16(0.15)$ \\
Medicare payer mix & $-0.012(0.001)^{\star \star \star}$ \\
Medicaid payer mix & $-0.012(0.005)^{\star \star}$ \\
Environmental characteristics & \\
HHI & $-0.16(0.04)^{\star \star \star}$ \\
Per capita income & $0.011(0.03)$ \\
Percent of population over 65 & $0.042(0.27)$ \\
Unemployment rate & $-0.03(0.011)^{\star \star \star}$ \\
Constant & $8.52)^{\star \star \star}$ \\
\hline \multirow{2}{*}{ P<0.01; } & \\
\hline
\end{tabular}

**, $\mathrm{P}<0.01 ;{ }^{* \star \star}, \mathrm{P}<0.001$. HHI, Herfindahl-Hirschman Index.

Table 5 Pairwise comparison of beta coefficients of the four strategic groups for operating margin $(\mathrm{N}=23,387)$

\begin{tabular}{lc} 
Strategic groups & Operating margin \\
\hline Differentiation vs. cost-leadership & 0.6 \\
Hybrid vs. cost-leadership & $0.41^{\star \star}$ \\
Hybrid vs. differentiation & -0.18 \\
Stuck-in-the-middle vs. cost-leadership & $-0.4^{\star *}$ \\
Stuck-in-the-middle vs. differentiation & $-0.986^{\star}$ \\
Stuck-in-the-middle $v s$. hybrid & $-0.79^{\star \star \star}$
\end{tabular}

*, $\mathrm{P}<0.05 ;$ **, $\mathrm{P}<0.01$; ${ }^{* *}, \mathrm{P}<0.001$.

0.97 percent lower operating margin $(\mathrm{P}<0.1)$ compared to hospitals in the differentiation strategic group. Finally, the result of the analyses supported our hypothesis. As is shown in Table 5, hospitals in the stuck-in-the-middle group have 0.79 percent less operating margin compared to hybrids
$(\mathrm{P}<0.05)$.

\section{Discussion}

In this longitudinal study, we examined the association between strategic group membership and hospital financial performance in terms of operating margin from 2006 to 2016. Our results suggest that strategic group membership may be an important factor associated with financial performance of urban acute care hospitals. More specifically, we found that: (I) most hospitals pursue a cost-leadership strategy, and the fewest hospitals pursue a differentiation strategy; (II) hospitals with hybrid strategy may outperform hospitals with cost-leadership strategy and stuck-in-themiddle; however, there our result did not show significant difference between hybrids and differentiators; and (III) the absence of a coherent strategy (i.e., stuck-in-the-middle) is likely to lead to poor performance. The implications of these findings are discussed below.

First, about 37 percent of hospitals each year were grouped in the cost-leadership strategic group (except the years 2008 and 2009). Only about 5 percent of hospitals were grouped in the differentiation strategic group each year. It seems that the strategy of overall cost leadership may have received much attention in the last decade. Hospital managers may have focused a great deal of attention on cost control measures to protect from competitive forces arising in this industry and to cope with regulatory changes that may have constrained their financial resources $(3,62)$. On the other hand, the differentiation strategy seems has not been commonly used. One reason could be the high cost of pursuing a pure differentiation strategy. Since hospital competition may lead to a medical arms race, where hospitals may duplicate each other at an escalating pace, it may be difficult to differentiate based on services.

Second, there was a noticeable fluctuation of hospital strategic group membership before 2010 (Figure 1), but membership seems to be stabilized after 2010. The fluctuation before 2010 could be related to the Great Recession of 2008 (63); the worst recession in the last 70 years of US history. Every revenue and capital source were at risk during this period, including reimbursement per discharge $(70 \%$ of hospitals reported moderate or significant increases in uncompensated care), number of inpatient admissions (over one-half reported a moderate or significant decrease), bond financing (60\% reported at least significant problems), and charitable donations. 


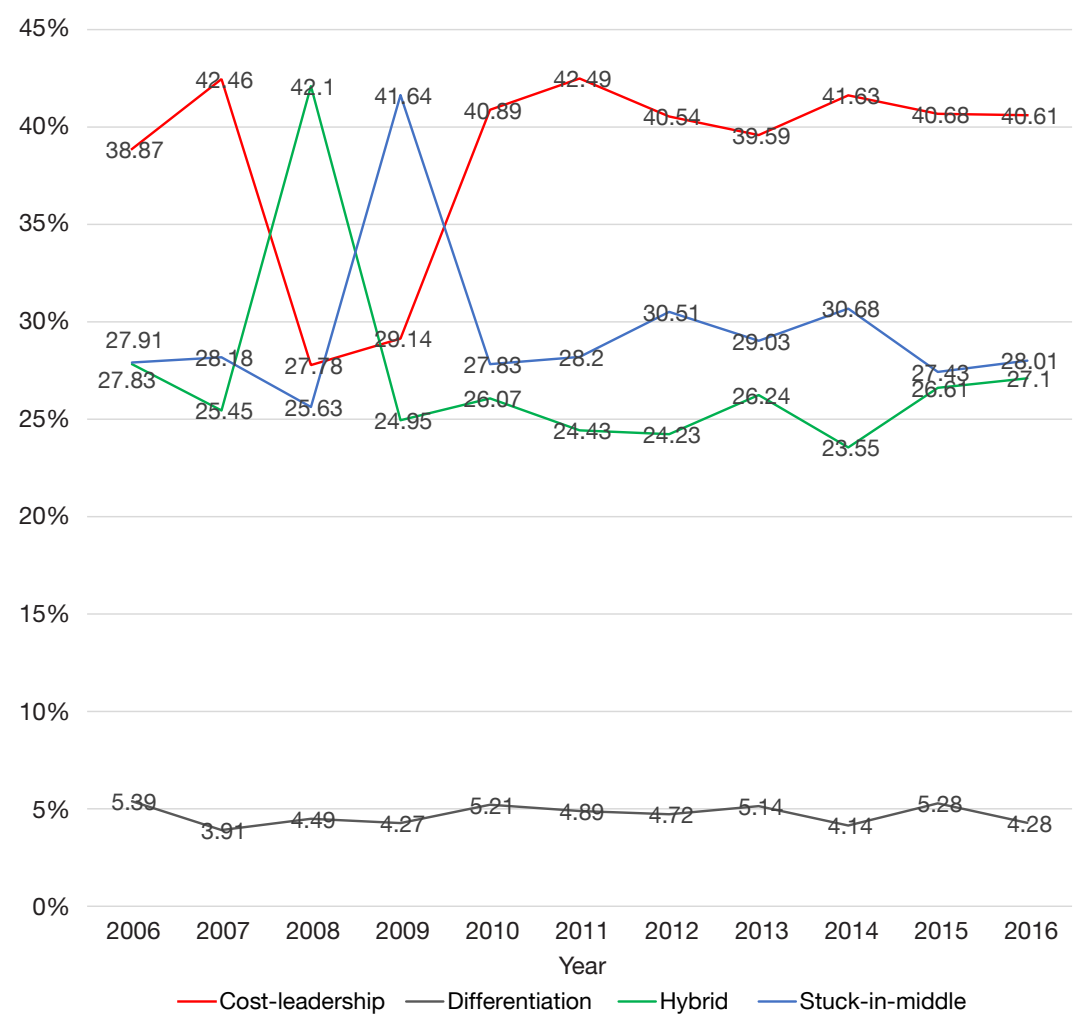

Figure 1 Fluctuation of four types of strategic groups between 2006 and 2016.

Besides, over $50 \%$ of US hospitals had negative margins in the fourth quarter of 2008 (64). These factors may have created uncertainty in the hospital markets. As such, hospital administrators may have been more reactive to the environment, and this may have resulted in hospitals not having consistent strategic positioning. On the other hand, economic recovery from the recession, as well as the implementation of the Affordable Care Act (2010) could be two main reasons for the stability of hospitals' strategy after 2010.

Third, our examination of the strategy and performance relationship revealed that pursuing a hybrid strategy may confer specific performance-related advantages upon hospitals competing in this industry. According to the literature, hospitals may pursue simultaneously both costleadership and differentiation strategies to gain competitive advantage and eventually outperform their rivals (31). The results of this study are aligned with those findings.

Fourth, the lack of a coherent strategy (i.e., stuckin-the-middle) is likely to lead to poor performance. According to our findings, hospitals in the costleadership, differentiation, and hybrid strategic groups seem outperformed hospitals in the stuck-in-the-middle strategic group. This result is aligned with Kumar and Subramanian (26). According to Porter (8), the benefits of optimizing a strategy cannot be gained if a hospital is simultaneously and unsuccessfully pursuing more than one generic strategy. Thus, hospitals should compete on one of the two generic strategies (cost leadership or differentiation) to have better financial performance (44). However, as our results showed, if hospitals successfully pursue both costleadership and differentiation strategy simultaneously, they may achieve better financial performance as well.

In summary, strategic group membership appears to be a helpful tool in predicting hospital financial performance. According to Porter's (8) typology, each strategy entails a different basis for achieving a competitive advantage and different strategies may result in variations of firm performance. Hospitals need different arrangements in organizational characteristics, such as offered services, procedures, structure, size, human resources, etc. to pursue a specific strategy. These organizational differences seem to impact their financial performance.

The need for hospital administrators to pay attention to 
Table 6 Correlation between cost leadership variables

\begin{tabular}{lccc}
\hline Variables & Total cost & Salaries & Total expenses \\
\hline Total cost per patient day & 1.0000 & - & - \\
Salary per patient day & 0.9716 & 1.0000 & - \\
Total expenses per & 0.7448 & 0.6121 & 1.0000 \\
occupied bed & & & \\
\hline
\end{tabular}

cost control is hardly new, but professional people involve in strategic planning of hospitals should recognize that it may be possible to increase their organization's revenuegenerating capacity by differentiating its products and services and pursuing cost control activities simultaneously. The result of this study showed that a solitary focus on efficiency or cost-minimizing may not be essential for financial success, and our study suggests that a relentless quest for efficiency or cost control may not be necessarily the best strategy. Since in the health care context customers are not price-sensitive they may want to receive the best available services. Since hospital markets lack price sensitivity as much as other industries for a variety of reasons, including lack of transparency of prices, payment through third-party insurance, and oligopolistic markets $(65,66)$, the strategy of cost-leadership may not be the best strategy for hospital administrators to pursue. Thus, hospital administrators should consider differentiating themselves from their rivals by reshaping their mix of services to provide a more attractive product mix, yet still considering whether and how that service mix will affect costs. In effect, then, hospital administrators should strive to channel their creative energies into continuous efficiency improvement. The conscious decision to provide a range of services implies deciding to offer both unique and ordinary services. However, providing unique and high technology services are very expensive and only large hospitals may be able to afford to provide such services. The alternative strategy could be a hybrid strategy. Hospitals can focus on their cost control by performing efficiently, and at the same time, they can invest in more services, high tech services, or quality of care.

Finally, as has been mentioned throughout the paper, pursuing a stuck-in-the-middle strategy is not the desired strategy for hospitals and according to our analysis, it leads to the worst financial performance. However, the results show that almost $28 \%$ of hospitals have been categorized in the stuck-in-the-middle group. Hospital's administrators need to understand that pursuing an appropriate strategy and eventually gaining a competitive advantage is a vital element to survive in the increasingly competitive environment of hospitals. In addition, hospitals need to invest time and effort to understand their capabilities, competitors, negotiating power, regulations, and demand for their services to proactively develop an appropriate strategy and improve their financial performance.

As with almost all studies, limitations were associated with the current study. First, one major limitation of this study was using secondary data. Inherent to the nature of secondary data, the available data are not collected to address the specific research question or to test certain hypotheses. For example, variables related to organizational behavior and leadership characteristics are not readily available for analysis. Using secondary data also has other limitations such as missing values and the retrospective nature of data. While examining hospitals at the national level increases the generalizability of findings, this type of study limits the ability to control for differences in regulations and other environmental factors among states (although we tried to address this limitation by controlling for state-level fixed effects). Second, to examine hospital strategic groups, we used three measures to operationalize the cost-leadership dimension and three measures to operationalize the differentiation dimension (descriptive statistics of cost leadership and differentiation variables can be seen in Tables 6-8). These measures were initially developed based on a review of the literature and consultations with industry experts in other studies $(27,49)$. However, future research should consider validating the resulting strategic group structure with qualitative data from hospital administrators. At a minimum, we hope that even with these limitations, the results of this study will serve as a point of reference for future studies on the strategy and financial performance relationship in the hospital industry and other industries.

\section{Conclusions}

Our study showed the importance of strategic group membership when examining hospital financial performance. Furthermore, our study provides a useful framework for managers to assess their current strategic positioning and potential implications for financial performance. Examining an industry's structure and the distinct strategies that are available, are important considerations for successful strategic management. Furthermore, if among these distinct strategies, some 
Table 7 Correlation between hospital beds and three variables of differentation

\begin{tabular}{lcccc}
\hline Variables & Hospital bed & Total services & High tech services & Rare services \\
\hline Hospital bed & 1.0000 & - & - & - \\
Total services & 0.7023 & 1.0000 & 1.0000 & - \\
High tech services & 0.6405 & 0.6803 & 0.675 & 1.0000 \\
Rare services & 0.7164 & 0.7002 & - \\
\hline
\end{tabular}

Table 8 Descriptive analysis of variables used for cost-leadership and differentiation dimesions

\begin{tabular}{|c|c|c|c|c|}
\hline Variables & Mean & Standard deviation & Min & Max \\
\hline High tech services & 1.89 & 0.98 & 0 & 4 \\
\hline Rare services & 3.39 & 3.6 & 0 & 26 \\
\hline Total cost per patient day & $8,105.87$ & $54,364.94$ & 100.31 & $2,061,398$ \\
\hline Total expenses per occupied bed & $1,118,041$ & $1,696,000$ & $12,616.32$ & $5.51 e+07$ \\
\hline
\end{tabular}

are more performance-enhancing than others, it may be important for hospital managers to understand the implications of their strategic positioning.

\section{Acknowledgments}

Funding: None.

\section{Footnote}

Peer Review File: Available at https://jhmhp.amegroups.com/ article/view/10.21037/jhmhp-21-71/prf

Conflicts of Interest: All authors have completed the ICMJE uniform disclosure form (available at https://jhmhp. amegroups.com/article/view/10.21037/jhmhp-21-71/coif). Robert Weech-Maldonado serves as an unpaid editorial board member of Fournal of Hospital Management and Health Policy from March 2021 to February 2023. The other authors have no conflicts of interest to declare.

Ethical Statement: The authors are accountable for all aspects of the work in ensuring that questions related to the accuracy or integrity of any part of the work are appropriately investigated and resolved.

Open Access Statement: This is an Open Access article distributed in accordance with the Creative Commons Attribution-NonCommercial-NoDerivs 4.0 International License (CC BY-NC-ND 4.0), which permits the noncommercial replication and distribution of the article with the strict proviso that no changes or edits are made and the original work is properly cited (including links to both the formal publication through the relevant DOI and the license). See: https://creativecommons.org/licenses/by-nc-nd/4.0/.

\section{References}

1. Lalani K. External environmental dimensions and financial performance of major teaching hospitals in the U.S. 2019. Available online: https://digitalcommons.library.tmc.edu/ uthsph_dissertsopen/204/

2. Al-Amin $M$, Housman $M$. Ambulatory surgery center and general hospital competition: entry decisions and strategic choices. Health Care Manage Rev 2012;37:223-34.

3. Blumenthal D, Abrams M, Nuzum R. The Affordable Care Act at 5 Years. N Engl J Med 2015;373:1580.

4. Topaloglu O, McDonald RE, Hunt SD. The theoretical foundations of nonprofit competition: A resourceadvantage theory approach. Journal of Nonprofit \& Public Sector Marketing 2018;30:229-50.

5. Goldstein SM, Ward PT, Leong GK, et al. The effect of location, strategy, and operations technology on hospital performance. J Oper Manag 2002;20:63-75. 
6. Richards CA. The effect of hospital financial distress on immediate breast reconstruction. Columbia: Columbia University, 2014.

7. Hunt MS. Competition in the major home appliance industry, 1960-1970. Harvard: Harvard University, 1972.

8. Porter ME. Competitive Strategy: Techniques for Analyzing Industries and Competitors. New York: Free Press, 1980.

9. Marlin D, Huonker JW, Hasbrouck RB. Navigating Turbulent Times: Strategic Groups and Performance in the Hospital Industry, 1983 to 1993 . Organizational Analysis 2004;12:91-107.

10. Marlin D, Huonker JW, Sun M. An examination of the relationship between strategic group membership and hospital performance. Health Care Manage Rev 2002;27:18-29.

11. Short JC, Palmer TB, Ketchen DJ Jr. Resource-based and strategic group influences on hospital performance. Health Care Manage Rev 2002;27:7-17.

12. Castle NG. Strategic groups and outcomes in nursing facilities. Health Care Manage Rev 2003;28:217-27.

13. Porter ME. From competitive advantage to corporate strategy. Readings in strategic management. Springer, 1989:234-55.

14. Porter ME. The five competitive forces that shape strategy. Harv Bus Rev 2008;86:78-93, 137.

15. Miller D. The structural and environmental correlates of business strategy. Strateg Manag J 1987;8:55-76.

16. McGee J, Thomas H. Strategic groups: theory, research and taxonomy. Strateg Manag J 1986;7:141-60.

17. Mascarenhas B, Aaker DA. Mobility barriers and strategic groups. Strateg Manag J 1989:475-85.

18. Olusoga SA, Mokwa MP, Noble CH. Strategic groups, mobility barriers, and competitive advantage: an empirical investigation. J Bus Res 1995;33:153-64.

19. Schreyögg J, von Reitzenstein C. Strategic groups and performance differences among academic medical centers. Health Care Manage Rev 2008;33:225-33.

20. Ketchen DJ, Thomas JB, Snow CC. Organizational configurations and performance: A comparison of theoretical approaches. Acad Manag J 1993;36:1278-313.

21. Herbert TT, Deresky H. Generic strategies: an empirical investigation of typology validity and strategy content. Strateg Manag J 1987;8:135-47.

22. Conant JS, Mokwa MP, Varadarajan PR. Strategic types, distinctive marketing competencies and organizational performance: a multiple measures-based study. Strateg Manag J 1990;11:365-83.
23. Beal RM. Competing effectively: environmental scanning, competitive strategy, and organizational performance in small manufacturing firms. Journal of Small Business Management 2000;38:27-47.

24. DESS GG, Davis PS. Strategic Group Membership and Organizational Performance1. Acad Manag J 1984;27:467-88.

25. Miller D, Friesen PH. Porter's (1980) generic strategies and performance: an empirical examination with American data: part I: testing Porter. Organization Studies 1986;7:37-55.

26. Kumar K, Subramanian R, Strandholm K. Competitive strategy, environmental scanning and performance: A context specific analysis of their relationship. Journal of Commerce and Management 2001;11:1-33.

27. Lamont BT, Marlin D, Hoffman JJ. Porter's generic strategies, discontinuous environments, and performance: a longitudinal study of changing strategies in the hospital industry. Health Serv Res 1993;28:623.

28. Mensa Sorato M, Davari M, Abdollahi Asl A, et al. Why healthcare market needs government intervention to improve access to essential medicines and healthcare efficiency: a scoping review from pharmaceutical price regulation perspective. J Pharm Health Serv Res 2020;11:321-33.

29. Chambers S. Why the Economic Aspects of Healthcare are not Unique. Sultan Qaboos Univ Med J 2020;20:e165-72.

30. Wright P, Kroll M, Kedia B, et al. Strategic profiles, market share, and business performance. Industrial Management 1990;32:23-8.

31. Kumar K, Subramanian R. Porter's strategic types: Differences in internal processes and their impact on performance. Journal of Applied Business Research 1997;14:107-23.

32. Fronsdal TL, Bhattacharya J, Tamang S. Variation in Health Care Prices Across Public and Private Payers. Cambridge, MA: National Bureau of Economic Research, 2020.

33. Belli P, Jeurissen P. Hospital Payment Systems. Understanding Hospitals in Changing Health Systems. Springer, 2020:121-38.

34. Fuller RL, McCullough EC, Averill RF. A new approach to reducing payments made to hospitals with high complication rates. Inquiry 2011;48:68-83.

35. Luft HS, Robinson JC, Garnick DW, et al. The role of specialized clinical services in competition among hospitals. Inquiry 1986;23:83-94. 
36. Trinh HQ, Begun JW. Strategic Differentiation of High-Tech Services in Local Hospital Markets. Inquiry 2019;56:46958019882591.

37. Tay L. Business performance of surveying firms: A data-driven path model. Journal of Property Research 2002;19:327-51.

38. Bronstein JM, Morrisey MA. Bypassing rural hospitals for obstetrics care. J Health Polit Policy Law 1991;16:87-118.

39. Folland ST. Predicting hospital market shares. Inquiry 1983;20:34-44.

40. Gelijns AC, Halm EA. The changing economics of medical technology. Washington (DC): National Academies Press (US), 1991.

41. Farley DE, Hogan C. Case-mix specialization in the market for hospital services. Health Serv Res 1990;25:757-83.

42. Luft HS, Robinson JC, Garnick DW, et al. Hospital behavior in a local market context. Med Care Rev 1986;43:217-51.

43. Robinson JC, Luft HS. The impact of hospital market structure on patient volume, average length of stay, and the cost of care. J Health Econ 1985;4:333-56.

44. Marlin D, Hoffman JJ, Lamont BT. Porter's generic strategies, dynamic environments, and performance: A profile deviation fit perspective. The International Journal of Organizational Analysis 1994;2:155-75.

45. Lapersonne A, Sanghavi N, De Mattos C. Hybrid Strategy, ambidexterity and environment: toward an integrated typology. Universal Journal of Management 2015;3:497-508.

46. Goes JB, Meyer AD, editors. Patterns of strategic change, environmental change, and performance: a longitudinal study of California hospitals. Academy of Management Annual Meeting Proceedings 1990(1):85-89.

47. Dess GG, Davis PS, editors. An Empirical Examination of Porter's (1980) Generic Strategies. Academy of Management Proceedings. Briarcliff Manor, NY: Academy of Management, 1982.

48. Ketchen DJ, Combs JG, Russell CJ, et al. Organizational configurations and performance: A meta-analysis. Acad Manag J 1997;40:223-40.

49. Landry AY, Hernandez SR, Shewchuk RM, et al. A configurational view of executive selection behaviours: a taxonomy of USA acute care hospitals. Health Serv Manage Res 2010;23:128-38.

50. Hatten JM, Connerton RE. Urban and rural hospitals: how do they differ? Health Care Financ Rev 1986;8:77-85.

51. Ramamonjiarivelo Z, Weech-Maldonado R, Hearld
L, et al. The Privatization of Public Hospitals: Its Impact on Financial Performance. Med Care Res Rev 2020;77:249-60.

52. Bazzoli GJ, Fareed N, Waters TM. Hospital financial performance in the recent recession and implications for institutions that remain financially weak. Health Aff (Millwood) 2014;33:739-45.

53. Forte M, Hoffman JJ, Lamont BT, et al. Organizational form and environment: an analysis of between-form and within-form responses to environmental change. Strateg Manag J 2000;21:753-73.

54. Zengul FD, Weech-Maldonado R, Ozaydin B, et al. Longitudinal analysis of high-technology medical services and hospital financial performance. Health Care Manage Rev 2018;43:2-11.

55. Gapenski LC, Pink GH. Understanding healthcare financial management. Chicago: Health Administration Press, 2007.

56. Vélez-González H, Pradhan R, Weech-Maldonado R. The role of non-financial performance measures in predicting hospital financial performance: the case of for-profit system hospitals. J Health Care Finance 2011;38:12-23.

57. Liu JB, Kelz RR. Types of Hospitals in the United States. JAMA 2018;320:1074.

58. Hair J, Black W, Babin B, et al. Multivariate Data Analysis. NJ, USA: Upper Saddle River, 1998.

59. Ghiasi A, Weech-Maldonado R, Hearld L, et al. The Moderating Effect of Environmental Instability on the Hospital Strategy-Financial Performance Relationship. Journal of Health Care Finance. 2019. Available online: http://healthfinancejournal.com/index.php/johcf/article/ view/202/205

60. Everhart D, Neff D, Al-Amin M, et al. The effects of nurse staffing on hospital financial performance: competitive versus less competitive markets. Health Care Manage Rev 2013;38:146-55.

61. Diggle P, Liang KY, Zeger SL. Longitudinal data analysis. New York: Oxford University Press, 1994;5:13.

62. Holzhacker M, Krishnan R, Mahlendorf MD. The impact of changes in regulation on cost behavior. Contemporary Accounting Research 2015;32:534-66.

63. Dunn D, Koepke D, Pickens G. The current recession and US hospitals. New York: Thomson Reuters, 2009.

64. Rees M, Tekkis PP, Welsh FK, et al. Evaluation of longterm survival after hepatic resection for metastatic colorectal cancer: a multifactorial model of 929 patients. Ann Surg 2008;247:125-35.

65. Zwanziger J, Melnick GA, Simonson L. Differentiation 
Page 14 of 14

and specialization in the California hospital industry 1983 to 1988. Med Care 1996;34:361-72.

66. Bai G, Patel P, Makary MA, et al. Providing useful

doi: $10.21037 /$ jhmhp-21-71

Cite this article as: Ghiasi A, Weech-Maldonado R, Zengul F, Puro N. The association between strategic group membership and hospital financial performance. J Hosp Manag Health Policy 2022;6:24.
Journal of Hospital Management and Health Policy, 2022

hospital pricing information to patients: lessons from voluntary price disclosure. Health Aff 2019. doi: 10.1377/ forefront.20190416.853636. 


\section{Decision criteria to identify the optimal cluster solution}

In conjunction with the visual inspection of the treeplots, we used the following decision criteria to identify an optimal cluster solution (67):

(I) Clusters explain at least $65 \%$ of the overall variance;

(II) An additional cluster increases the overall fit by less than $5 \%$;

(III) A local peak in the Cubic Clustering Criterion: The cubic clustering criterion (CCC) is used to estimate the number of clusters using Ward's minimum variance method, $\mathrm{k}$-means, or other methods based on minimizing the within-cluster sum of squares. Local peak in the Cubic Clustering Criterion shows the minimum within-cluster sum of squares (67);

(IV) A local peak in the pseudo-F statistic. The pseudo-F statistic describes the ratio of betweencluster variance within-cluster variance. Peaks in the pseudo-F statistic are indicators of greater cluster separation $(67,68)$;

(V) A small value of the pseudo $\mathrm{t}^{\wedge}$ statistic and a larger pseudo $\mathrm{t}^{\wedge}$ statistic for the next cluster fusion. This index quantifies the difference between two clusters that are merged at a given step. Thus, if the pseudo-T-square statistic has a distinct jump at step $\mathrm{k}$ of the hierarchical clustering, then the clustering in step $\mathrm{k}+1$ is selected as the optimal cluster $(67,68)$.

If inconsistencies existed across these rules, we relied on visual inspection of the tree-plots and prioritized our use of each rule in the order in which they are listed above. These decision criteria are consistent with those used in prior strategic group research $(9,20,53,69)$, and with clustering stopping rules recommended by the SAS Manual and by the SAS Technical Report A-108 (67). Our analysis showed that a four-group solution was the optimal cluster solution each year.

\section{References}

67. SAS Institute Inc. 2017. SAS® Enterprise Miner ${ }^{\mathrm{TM}}$ 14.3: Reference Help. Cary, NC: SAS Institute Inc., 2017.

68. Davies DL, Bouldin DW. A cluster separation measure.

IEEE Transactions on Pattern Analysis and Machine

Intelligence 1979;PAMI-1:224-7. doi: 10.1109/

TPAMI.1979.4766909.

69. Kumar K, Subramanian R, Yauger C. Pure versus hybrid: performance implications of Porter's generic strategies. Health Care Manage Rev 1997;22:47-60. 